\title{
A cultural exploration of the national institutes of health neuropsychological cognition battery assessments in India
}

\author{
Saajan H. Bhakta ${ }^{1 *}$, Viviane de Castro Pecanha², Sagar S. Lad ${ }^{3}$, \\ Vidyulata Kamath ${ }^{4}$
}

\section{ABSTRACT}

Cross-cultural exploration and adaptation of psychological tests and assessments is critical to ensure accurate and reliable results. This research study conducted a qualitative cultural exploration of the National Institutes of Health (NIH) Toolbox Cognition Battery assessments in India as an initial step towards the cultural adaptation and validation of the instruments. As the assessments were developed in the United States, they required cultural exploration before they were used in India. Using interpretive phenomenological analysis, the study included a sample of 30 participants across Mumbai, Surat, and Derod. Five themes emerged from the data analysis: contentedness, lack of relatability, recommendations for change, the rural Indian lifestyle, and the variable of education. The most common code was "satisfied." While this research does indicate that participants comprehend the assessments, recommendations were made to change images and storylines to reflect the Indian culture. They focused on Indian food, Indian clothing, Indian festivals, family, and religion in India. The findings from this study can be used to inform future adaptation and validation of the National Institutes of Health (NIH) Toolbox Cognition Battery assessments in India.

\section{Keywords: Cognition, Cross-Cultural Validation, India, Neuropsychology, NIH Toolbox}

$\mathbf{I}^{\mathrm{n}}$ $\mathrm{n}$ an increasingly diverse, complex, and ever-changing world, psychological instruments, evaluations, and tools must be cross-culturally explored and validated to ensure validity and reliability before use across diverse populations. Particularly the tools and instruments developed in English. Such instruments cannot be assumed to be appropriate, valid, and reliable in non-Western societies and English-speaking cultures (Ogden \& McFarlane-Nathan, 1997). In fact, using neuropsychological tests for populations and cultures other than those for which they have been normed or standardized can result in clinical diagnostic errors (Ogden \& McFarlane-Nathan, 1997). Cross-cultural validation focuses on whether or not measures and constructs that were developed in a specific culture are relevant, meaningful, and, as a result, applicable to other cultures (Mastumoto, 2003). Without cross-cultural validation,

\footnotetext{
${ }^{1}$ The Chicago School of Professional Psychology, Chicago, IL, USA

${ }^{2}$ The Chicago School of Professional Psychology, Chicago, IL, USA

${ }^{3}$ W. G. (Bill) Hefner VA Healthcare System, Salisbury, NC, USA

${ }^{4}$ The Johns Hopkins University School of Medicine, Baltimore, MD, USA

*Responding Author
}

Received: August 24, 2020; Revision Received: September 21, 2020; Accepted: September 25, 2020

(C) 2020, Bhakta S.H, Pecanha V.D.C, Lad S.S. \& Kamath V.; licensee IJIP. This is an Open Access Research distributed under the terms of the Creative Commons Attribution License (www.creativecommons.org/licenses/by/2.0), which permits unrestricted use, distribution, and reproduction in any Medium, provided the original work is properly cited. 


\section{A cultural exploration of the national institutes of health neuropsychological cognition battery assessments in India}

instruments can produce false or invalid results, and use of these instruments can lead to misdiagnoses or negative implications for individuals, communities, and even entire populations.

This research study falls under the field of international psychology, which is a relatively new branch of psychology in which psychologists understand that psychological phenomena are not geographically bound. Scholars in the field aim to study, understand, and respond to the important topics and challenges of psychology from a global perspective and approach with the understanding that context plays a shaping role in human behavior (Stevens \& Wedding, 2004; Stevens \& Zeinoun, 2013). Cultural, cross-cultural, and indigenous psychologies are incorporated in and serve international psychology in scope and approach (Stevens \& Wedding, 2004). The process and goal of culturally exploring assessments across different cultures inherently acknowledges that psychological processes do not exist in a vacuum. In this particular research study, the culture of India is presented as independent from any Western culture.

This research study aimed to contribute to the field of international psychology by taking necessary steps towards informed practice across diverse cultures. It is in line with the goals of internationalizing psychology. Internationalizing psychology is the corrective process that safeguards the field against provincialism and obsolescence by focusing on contextualization (Stevens \& Zeinoun, 2013). As a preliminary step towards the potential adaptation and validation of the NIH Toolbox Cognition Battery, the study aimed to internationalize psychology by studying and researching the Western-developed assessment's suitability for its application in India.

Individuals across cultures build their knowledge in various ways depending on their environment and surroundings (Raskin, 2002). Constructivist theory and psychologies convey that human beings use their experiences to assign and create meanings for the world and realities around them (Raskin, 2002). Constructivists uphold the viewpoint that individuals build their knowledge rather than being imprinted with a specific set of knowledge at birth (Cobern, 1991). For example, executive functions such as self-awareness, nonverbal working memory, and inhibition are linked to and shaped by parental and cultural influences (Ellefson, $\mathrm{Ng}$, Wang, \& Hughes, 2017), and psychological assessments and tools must account for these factors.

Specifically, differences exist between Eastern and Western adults with regard to attentional and cognitive processing (Kuwabara \& Smith, 2012). Eastern adults demonstrate relational cognition when compared to Western adults who tend to be more object focused (Kuwabara $\&$ Smith, 2012). For example, if shown a photo of a farm, Eastern adults may interpret a farm horse within the context or in relation to its surroundings on the working farm, while Western adults may focus on the animal itself without necessarily taking the other farm environment into consideration. To add, the degree to which adults emphasize decontextualized versus contextualized interpretations of objects varies amongst Eastern and Western adults (Kuwabara \& Smith, 2012).

As an example, Masuda and Nisbett (2001) found significant differences in adults living in the United States and adults in Japan in their description of an aquarium. The adults in the United States focused on the larger fish in the middle of the display as the foundation for their description while the Japanese adults focused on describing the large fish in the center of the 


\section{A cultural exploration of the national institutes of health neuropsychological cognition battery assessments in India}

aquarium in relation to the items around it such as other plants and smaller fish (Masuda \& Nisbett, 2001). Both groups described the large fish, but those from the United States did not take the small plants and other fish into consideration in their description while the Japanese adults did.

Differences in cognitive spatial volume perception between Eastern and Western cultures also exist. Using a psychological task that asked participants to judge whether a rectangular room was larger or smaller than a square room of reference, there were significant differences in responses between South Koreans and Germans due to cultural perspectives. The findings from this study indicated that the South Koreans were more contextual in their review. This led researchers to further support the concept that Eastern cultures are more context dependent than Western cultures (Saulton, Bülthoff, De la Rosa, Dodds, \& Herzog, 2017). There is a vast amount of literature that supports the idea that time perception also varies across cultures at the cognitive level (Núñez \& Cooperrider, 2013). Looking at the domain of emotion, culture influences emotions through different cognitive mechanisms that have been supported by existing literature (Engelmann \& Pogosyan, 2013). Responses on processing speed tasks are also different across Eastern and Western cultures (Papadopoulos, Georgiou, Deng, \& Das, 2018). These differences in cognition reveal the need for culturally sensitive assessments, tests, and instruments.

Given this significant need for effective, accessible, and relevant neuroscience measurement tools, in 2004, the 15 Institutes, Centers, and Offices at NIH that work to support neuroscience research created a coalition named the Blueprint for Neuroscience Research. In 2006, the coalition was awarded grant funding to develop a set of state-of-the-art tools to enhance the field of neuropsychological research. The NIH aimed to work towards bridging this gap by creating an innovative set of batteries and assessments to measure cognitive, emotional, motor, and sensory function. The NIH Toolbox is a group set of neurobehavioral tests that assess cognitive, emotional, sensory, and motor functions through the use and convenience of a tablet (Northwestern University, 2019). The Toolbox's Cognition Battery has been selected for this cultural exploration due to its digital and technological nature making it relatively easy to administer with a tablet. In an increasingly complex world, convenience and accessibility are important factors, especially in low- and middle-income countries where gaps in care may exist due to funding and resource limitations (Siriwardhana et al., 2011). The Toolbox helps bridge this gap by making the neuropsychological assessment more easily accessible to the professional and research community due to its digital and free nature.

Cultural variances exist in performances across neuropsychological measures (Agranovich, Panter, Puente, \& Touradji, 2011), and it is imperative that exploration, adaptation, and validation of neuropsychological assessments occur before they are used across cultures. The NIH Toolbox Cognition Battery has not been explored for cultural relevance (Sharp, Skinner, Serekoane, \& Ross, 2011) in India. This research study aimed to culturally explore the NIH cognitive assessments across the adult population in India in order to determine the needs for future adaptations (Sullivan, 2011). Khilari and Narayan (2014) expressed concerns with the applicability of the NIH Toolbox within the Indian context. They argued that the use of Western cognitive instruments in a non-Western culture requires a careful analysis of its appropriateness before it can be effectively and reliably used (Khilari \& Narayan, 2014). Therefore, it is critical that a careful analysis of the cultural relevance of the assessments be conducted in India. 


\section{A cultural exploration of the national institutes of health neuropsychological cognition battery assessments in India}

Neuropsychological assessments can have influential, long-term impacts on an individual's life; therefore, attempts must be made to ensure that they are as culturally unbiased as possible to increase confidence in the test usage. When test scores are affected by demographic factors, test bias surfaces (Geisinger, 1992). In such cases, there may be bias related to the various batteries and neuropsychological assessments when the scores are influenced and developed by Western culture, independent of the influence of the ability or trait that the test is supposed to measure (Geisinger, 1992). In order to know whether a test, assessment, or battery is biased towards a certain group, it must be psychometrically tested in that population of interest (Geisinger, 1992).

There is a profound agreement that many neuropsychological assessments do not have acceptable reliability and validity with diverse populations. Hence, there is a significant need for this area of research given that over 30 million people have some form of neurological disorder in India (Gourie-Devi, 2014). Among these 30 million people, cognitive deficits have been confirmed in various psychiatric disorders (Dalal \& Sivakumar, 2010). As such, the cognitive assessments and batteries being used in India must be clinically sensitive and accurate to best help psychological professionals develop treatment plans.

Research has shown that performance on language-mediated neuropsychological assessment tasks is impacted by whether or not an individual is a native English speaker (Kisser, Wendell, Spencer, \& Waldstein, 2012). Native English speakers outperformed nonnative English speakers on a number of language-mediated tasks (Kisser et al., 2012). Shuttleworth-Edwards et al. (2004) found that scores on intelligence quotient (IQ) testing were impacted by culture. Similar to the use of Western cognition assessments across non-Western cultures, it can be challenging and misleading to use Western IQ testing with non-Western cultures (Kendall, Verster, \& Von Mollendorf, 1988). These populations, such as nonnative English speakers, differ from the Western cultures where assessments have historically been developed and normed. Examples of diverse populations include individuals who are not Caucasian, who are nonnative English-speakers, who are not well-educated, and who are not a part of the middle to upper class (Ardila, Rodriguez-Menendez, \& Rosselli, 2002; Boone, Victor, Wen, Razani, \& Pontón, 2007; Brickman, Cabo, \& Manly, 2006; Loewenstein, Arguelles, Arguelles, \& Linn-Fuentes, 1994; Manly, 2005). Manly (2008) argued, "Addressing cultural diversity in cognitive test performance is an unavoidable future of neuropsychological research and practice" (p. 179).

The NIH Toolbox Cognition Battery seeks to assess mental processes involved in gaining knowledge and comprehension, including remembering, problem-solving, thinking, judging, and knowing. Language, perceptions, imagination, and the planning and execution of complex behaviors are all encompassed in these higher-level functions, and all of these higherlevel functions of the brain are influenced and impacted by culture (Lewis et al., 2009). Although the NIH Toolbox Cognition Battery is relatively accessible for use across the globe through the convenience of a tablet, is currently only normed for the U.S. population. It has not been cross-culturally explored in India. Using the NIH Toolbox Cognition Battery without cross-cultural exploration or validation limits the validity and reliability of performance and interpretation of results because the evaluation was developed and normed using a Western lens and population, potentially impacting participant experience and scores. As a result, the battery must be culturally examined prior to use within India. 


\section{A cultural exploration of the national institutes of health neuropsychological cognition battery assessments in India}

The field of cross-cultural neuropsychology needs to address the normalization of current basic neuropsychological instruments across and within diverse cultural contexts (Ardila, 2002). Cultural exploration, adaptation, and validation of current basic neuropsychological instruments will allow the research community to inform professional practice, and in turn, potentially enhance the quality of life for individuals.

Although the use of a digital neuropsychological evaluation can seem effective from a time, cost, and resource perspective (Pade, 2016), it must first be explored within the culture it will be used. Therefore, the purpose of this research study was to explore the utility, sensitivity, and relevance of the NIH Toolbox Cognition Battery for individuals of Indian descent living in India. The findings from this research provide insight to adapt the instruments prior to widespread use across India by practitioners and professionals. Although cognitive assessments such as the Hindi Mental State Examination or Montreal Cognitive Assessment have been translated for use in India, they are pencil-and-paper tests (Porrselvi \& Shankar, 2017). India has a number of assessments which have been normed for use (Porrselvi \& Shankar, 2017); however, to keep up with the rapidly changing world, exploring the cultural utility of this digital assessment can create even more widespread access to needed mental healthcare (Porrselvi \& Shankar, 2017). The motivation for exploring the NIH Toolbox from a cultural perspective is its accessibility in being administered electronically, which differentiates this assessment from the others which have been studied and validated in India.

\section{METHODOLOGY}

\section{Sample}

After Institutional Review Board approval was granted by The Chicago School of Professional Psychology, data was collected in January of 2020. The population of interest for this research study was the overall population of India, and the sample included 30 participants equality distributed from a large urban city, a smaller rural city, and a rural village in India. The number of participants considered the recommendations provided by Larkin, Watts, and Clifton (2006). The authors argued that interpretative phenomenological analysis research generally involves a highly intensive and detailed analysis of the data that are collected from a small number of participants.

A representative or random sample is not necessary for interpretive phenomenological analysis because there is a need for a homogenous, purposive sample (Chapman \& Smith, 2002; Smith \& Osborn, 2004). Therefore, the purposive sampling technique is ideal for the study methodology (Creswell, 2009). In addition, convenience sampling technique was used for this research study. The goal was to understand specific lived experiences for specific identified cultural groups in India. Smith and Osborn (2004) referred to this as thinking in terms of theoretical rather than empirical generalizability. They wrote, "The readers make links between the findings of an IPA study, their own personal and professional experience, and the claims in the extant literature" (Smith \& Osborn, 2004, p. 56).

There is no right, wrong, or perfect sample size for an interpretative phenomenological study (Chapman \& Smith, 2002; Smith \& Osborn, 2004). Due to the involved, complex nature of collecting and analyzing rich, robust qualitative data, many researchers prefer a smaller sample size for practicality and resource considerations. Smith and Osborn (2004) shared that new researchers can easily become overwhelmed by vast amounts of data with large sample sizes, and as a result, they are unable to produce meaningful or penetrating analysis. Saturation (Mason, 2010; Saunders et al., 2018) and informational redundancy is the point at which no 


\section{A cultural exploration of the national institutes of health neuropsychological cognition battery assessments in India}

new information or themes emerge from iterative or repeated research. This is a gold standard in qualitative research (Creswell, 2007; Walker, 2012). Failure to achieve saturation can have a negative impact on the validity of the qualitative research study (Patricia \& Lawrence, 2015). Saturation was achieved in this study by having an adequate sample size. No new themes emerged after the $25^{\text {th }}$ participant. Charmaz (2006) argued that saturation is achieved "when gathering fresh data no longer sparks new theoretical insights, nor reveals new properties of your core theoretical categories" (p. 113). Saunders et al. (2018) argued that achieving saturation with interpretative phenomenological analysis is not straightforward and challenging, but saturation should be assessed across cases, not within them. While saturation can be achieved with as few as 16 participants, 20 to 40 participants may be necessary to achieve saturation across multiple sites (Hagaman \& Wutich, 2016). This research study included 30 participants across the sites.

Information power is another metric that is used in qualitative research to determine sample size. This is a concept that indicates that the more relevant information the sample holds, the lower number of participants is needed (Ann, Kirsti, \& Volkert, 2016). In this particular study, all of the participants were prescreened to ask if they were born in the Indian culture. As such, they theoretically held a wealth of relevant, important knowledge. In addition, as the focus of the study was to understand the cultural relevance of the NIH Toolbox in India, this knowledge is directly related to their ability to share information with the researcher. The inclusion criteria for this study were as follows: participants were between the ages of 18-85, born in India and raised by Indian parents, had the basic technical knowledge and educational level (completed the fifth grade) to use an iPad, had basic comprehension and communication skills in English, and did not have any known cognitive impairments (e.g., dementia, developmental disorders, motor skill disorders) as disclosed by self-report. For the purpose of this study, basic technical skills were defined as the ability to follow prompts from the iPad, tap the screen when directed, and listen to audio commands from the iPad. A basic educational level was defined as completion of the fifth grade, which is the completion of upper primary school in India.

Mumbai is a large, urban city while Surat is a smaller city in a different state of India that brings together people from many surrounding rural areas. Furthermore, Derod is a rural village of India that includes a different demographic of Indians. Using three diverse areas allowed for the inclusion of participants from both urban and rural areas of India. The sample included Indians who were born in India as revealed through self-report. The sample included diverse individuals from throughout the community, across the age span, and did not include exclusively university students as such samples can be problematic and nonrepresentative (Hanel \& Vione, 2016). By recruiting participants from beyond university classrooms, findings are more likely to have greater utility across a generalizable sample (Hanel \& Vione, 2016).

Table 1 Demographic Information of the Sample

\begin{tabular}{llll}
\hline Gender & $\mathbf{N}$ & \% & \\
\hline Female & 16 & 53.3 & \\
Male & 14 & 46.6 & SD \\
Age & Range & Mean & 14.11 \\
$(\boldsymbol{N}=\mathbf{3 0})$ & $19-76$ & 29.47 & \\
\hline
\end{tabular}




\section{A cultural exploration of the national institutes of health neuropsychological cognition battery assessments in India}

\section{Instrument}

According to existing literature, semi-structured interviews are the exemplary model for data collection with interpretive phenomenological analysis (Smith \& Osborn, 2004). Semistructured and open-ended interviews have become a gold standard for qualitative research (Affleck, Glass, \& MacDonald, 2013). The goal is to understand the experience of sensemaking and experience related to taking the NIH Toolbox assessments, so it is critical that the researcher be able to probe for important potential clarifications during the interview. Qualitative interviews allow participants the opportunity to "speak in their own voice and express their own thoughts and feelings" (Berg, 2007, p. 96). Each interview lasted approximately $1 \mathrm{hr}$ in duration. In qualitative research, the researcher is the primary tool and instrument (Creswell, 2007); however, software systems such as MAXQDA and NVivo can be used for organization purposes. For this research study, MAXQDA was used to digitally code information from the narrative interview transcripts. Qualitative research interviews are valuable for several reasons, but primarily they offer helpful information to understand the lives and worlds of others ( $\mathrm{Qu} \&$ Dumay, 2011). The process of conducting qualitative interviews requires careful, extensive planning, but it also requires "a respect for and curiosity about what people say, and a systematic effort to really hear and understand what people tell you" (Rubin \& Rubin, 1995, p. 17).

Using McNamara's (2009) general guidelines and best practices for conducting qualitative interviews, the interviews were conducted in a private setting to avoid distractions and privacy breaches. In the opening script of each interview, the interviewer explained the purpose of the study, addressed confidentiality, explained the structure and format of the interview, and outlined the time frame for the interview. In the closing script of the interview, the interviewer informed the participant how they could contact the research team after their departure if they needed to do so (McNamara, 2009).

Audio recording of interviews is not required for interpretative phenomenological analysis studies, but it can be helpful (Smith \& Osborn, 2004). During the interviews, participants were asked to share a pseudonym of their choice for use during the interaction (Jan, 2000). This protected their identity throughout the interview process (Jan, 2000). To increase validity of the research, the interviews were recorded using a voice recorder. They were then transcribed by a third party. The third-party transcriptionists were recruited using online platforms for hiring freelance transcriptionists. Upwork was the primary online platform that was used for recruitment. The use of third-party transcriptionists lent credibility to the narrative data and excluded the researcher as having researcher bias or access to changing any information prior to the analysis (Tessier, 2012).

\section{Procedure}

The NIH Toolbox Cognition Battery was administered on a tablet. One tablet was loaded with the application and battery. Once the researcher arrived at each data collection site, he set up a workstation in a private, quiet environment. The private room included a desk and two chairs. It had a door that closed to ensure privacy. Examples of data collection sites include universities, hospital conference rooms, and meeting rooms at community and cultural centers in India.

The instrument used and culturally explored in this research was the NIH Toolbox Cognition Battery. This tool has been validated for measuring executive function in adults from the US (Zelazo et al., 2014); the cognitive battery was originally validated using 268 adults 


\section{A cultural exploration of the national institutes of health neuropsychological cognition battery assessments in India}

(Weintraub et al., 2014). Although this instrument has been translated into Spanish, translation or construct validity and reliability testing has not yet been researched in India.

The battery was administered in English. English is an official language of India (Government of India, 1950), and most of higher education and corporate affairs are conducted in English (Latha, 2018). Given the many different dialects of the various languages in India, measuring validity of the battery in English provided more utility for preliminary research than translating it and administering to a smaller population that only speaks a certain dialect of one of the many languages of India. Furthermore, given the increasing prevalence of the English language in India (Latha, 2018), the results of administering it in English will hold greater value for future planning and use of the battery. This was a preliminary research study for the utility of this test in India, and future research is encouraged for translation.

Upon arrival, each participant was given an informed consent form to read, review, ask questions, and sign. Following this important step, each participant completed a selfdisclosure screening questionnaire. The questionnaire asked their gender, age, whether or not they had any known cognitive impairments, whether or not they were raised and reared by Indian parents in India, their country of birth, and their fluency in English. No identifying information was asked on the screening questionnaire. After the researcher reviewed the screening questionnaire to confirm inclusion in the research study, the researcher began the interview. Each interview was scheduled for $1 \mathrm{hr}$ with 15 min breaks in between the interviews to accommodate for potential delays or deviations from the schedule. The participants took each assessment on the tablet. After each assessment, the researcher asked the series of qualitative questions to better understand their experience. This process was repeated for each of the four subdomains being explored. If the participant did not understand any terms in the interview questions, the researcher stopped to explain and clarify. Coming from the Indian culture, and as a native speaker of both Hindi and Gujarati, the researcher was able to clarify terms from the interview questions in both languages if necessary.

Once the participant had the chance to debrief and ask any questions, they were released from the study. Stress from taking part in the study was not anticipated but checking in with the participants after their participation was simply a check in to see how they were doing, not an emotional or psychological assessment. No follow-up was necessary after their departure. Integrity, privacy, and confidentiality of the scores were based on tablet password protection when not in use, and the tablet was secured with the researcher between testing days.

Upon transcription completion, the data were cleaned and formatted. After the transcripts were completed, they were sent back to the participants via email for member checking to increase the credibility of this research study as recommended by Birt et al. (2016). This was the process of having participants review their own interview transcripts for accuracy (Birt et al., 2016). Participants returned their transcripts to the researcher within two weeks. There were no discrepancies reported by the participants, and they agreed that the transcripts reflected what they shared in the interview. As anticipated, saturation was achieved during data collection between participants' narratives, experiences, and recommendations for adaptation.

Participants' narratives were analyzed using Saldaña's (2016) coding manual and framework. The transcribed files were used for the coding process. For this exploratory research, inductive coding was used (Saldaña, 2016). A code is a researcher-generated construct that symbolizes or "translates" data (Vogt, Vogt, Gardner, \& Haeffele, 2014, p. 13) in qualitative analysis.

(c) The International Journal of Indian Psychology, ISSN 2348-5396 (e)| ISSN: 2349-3429 (p) | 1569 


\section{A cultural exploration of the national institutes of health neuropsychological cognition battery assessments in India}

These codes were important links between data collection and explanation of meaning (Charmaz, 2006).

Braun and Clarke (2006) argued that it is important to read every transcript at least once before starting the coding process. This is because the first reading can inform patterns and trends from a very high level. The first reading also ensured that the transcriptions were free from errors and formatting problems. Files were then sent to participants for member checking after being formatted. Once the participants confirmed that the transcripts were accurate, the researcher imported them into the MAXQDA software. The first step included initial coding of the data, and this took place during the second reading of each transcript. Considering that inductive coding was used, an initial codebook was not developed. This was intentional in order to allow the raw data to be read, interpreted, and analyzed without the goal of looking for predetermined codes.

In MAXQDA, initial codes were developed and added into the code system as the content analysis and read through took place. Following initial open coding, line-by-line coding took place. During this read through, each line of each interview was read out loud while considering any possible codes that could have been assigned. If a code came to mind that was not already in the code system from the initial coding review, it was added as a new code. Line by line analysis is important in order to identify emergent themes and the structural, thematic relationships between the themes (Smith et al., 2009). The third phase of data analysis was categorization. Using the categorization tool in MAXQDA, patterns that were observed in the data were grouped into meaningful units or categories (Given, 2008). Codes were placed into categories based on content similarity. Lincoln and Guba (1985) argued that the researcher uses intuitive senses and classification reasoning to categorize which data "look alike" and "feel alike" (p. 347). The final stage of identifying and creating themes was done using MAXQDA's summary function. This function assisted the researcher in creating a summary and creating the results table based on the summaries.

\section{RESULTS}

Five themes emerged from the participants' narratives. A total of 24 codes emerged from the dataset across all 30 participants. From those 24 codes, five themes were discovered. The five themes included contentedness, lack of relatability, recommendations for change, the rural Indian lifestyle, and the variable of education.

The most frequently occurring code in the data was "satisfied." No participant expressed that they felt the assessments were culturally inappropriate or disrespectful. They were content with the assessments, but the other codes, especially in relation to recommendations for changes, revealed the theme of lack of relatability. This theme reveals that while the assessments do have room for changes to be made more culturally relevant in India, how they exist in their current form does not cause harm or negative feelings from participants born, raised, and currently living in India.

Many participants expressed the importance of assessment translation to Hindi prior to widespread use in India due to the population in rural parts of the country who do not speak English. This code surfaced a total of 10 times across the dataset. A 43-year-old woman shared, "One thing you can translate this thing even in Hindi or any local language regional languages so that you can get more response." A 24-year-old man shared expressed, "If it is in English, there might be a problem for common people. A translation into Hindi would be 


\section{A cultural exploration of the national institutes of health neuropsychological cognition battery assessments in India}

better. It will be better in Hindi for people here in India." While they understood that the justification for this study being conducted in English was to study the assessments as they existed today, the recommendation to translate continued to be a heavy remark.

Attention: The Flanker Inhibitory Control and Attention Test (Weintraub et al., 2013; Zelazo et al., 2014) was used to measure the cognitive domain of attention. The test instructed participants to focus their attention on the screen and observe a row of arrows that pointed in various directions (e.g., same direction and different directions). Participants were tasked with selecting the direction of the middle arrow's point. This assessment did not include any other images. All 30 participants expressed that the test was clear and culturally relevant for use in India. The qualitative interviews after this particular assessment yielded the least feedback as most participants answered with simple "yes" or "no" responses. One participant shared that arrows were culturally relevant and a critical part of Indian history. She stated, "It is not a new sign for India. If we look at history, the warriors of India have used arrows to kill enemies. It is not a new symbol for India." Based on the feedback from all 30 participants, there were no recommendations or suggestions made to revise or adapt this test in order to make it more culturally appropriate for use in India. However, participants did encourage future researchers to adapt the test into Hindi for more widespread use, especially across rural parts of India.

Episodic Memory: The Picture Sequence Memory Test (Dikmen et al., 2014) was used to measure the cognitive domain of episodic memory. Overall, more than $90 \%$ of participants felt that this assessment was clear, but more than $95 \%$ of participants made suggestions and recommendations for adaptations in order to make it more culturally appropriate. Most participants identified with the story of playing in the park, but many participants did not identify with the story of going camping. The act of camping is a very recent trend in India, especially in the more rural parts of India, and many participants had never experienced camping (e.g., hiking or roasting a marshmallow). Furthermore, one participant was concerned by the marshmallows as they contain eggs, especially because India is primarily a vegetarian society. He expressed, "Roasting marshmallows is not appropriate. Indian people are very vegetarian. They do not know about marshmallows. Rather, you should use fresh vegetables." Participants did make detailed recommendations about storylines that would be better fit with the Indian culture. A male participant who was 57 years old shared "I think some might have a problem [understanding] because they do not go camping very much in this country. So, you would want to change those pictures into some sort of game in India. You know, maybe soccer or cricket." To demonstrate that this perspective was shared by other participants, another response by a participant (female) was, "Replace the baseball with sports like cricket. Another sport that is played in India is football. Indian people are crazy about football." There were no notable or significant differences related to gender in terms of recommendations. Younger participants identified with the camping storyline more so than older participants as camping was a part of their experiences, but this was not significant enough to result in confusion or cultural inappropriateness for the older participants. A 57year-old male participant noted cultural relatability between the photo of flying a kite and an annual festival and holiday called Makar Sankranti, which is focused on flying kites (Desai, 2010). The participant stated, "I think flying a kite is very good for India because everybody [does it] once a year."

Participants made similar notable comments regarding inclusion of Indian festivals and holidays as an appropriate step. Gentle probing about specific festivals revealed two common festivals, Diwali and Holi. Diwali is the festival of lights, which is celebrated each year in the 


\section{A cultural exploration of the national institutes of health neuropsychological cognition battery assessments in India}

fall (Peterson, 1995), and Holi is the festival of colors to celebrate the arrival of spring in India (Krishnaswami, 2001). One participant shared, "We are very attracted to festivals like Diwali. There are diyas that we light. There is rangoli. Pictures of the lamps and pictures of Indian rangoli design." When queried about specific images that could represent Diwali, common responses included traditional Indian candle lamps, known as diyas, and rangoli patterns. Rangoli is traditional Indian art that uses geometric shapes and is commonly created with colored powder on the floor as decoration (Redwood, Gale, \& Greenfield, 2012). Participants shared that colored powder and rangoli were relatable images that most Indians living in India would understand.

Participants also shared that football and soccer are not widespread or commonly played in India. For adaptation in India, the participants recommended cricket balls. Cricket is a popular sport played around the Eastern world, and cultivated interest in India during English colonization. Many participants were certain that this would be a recognizable and relatable image for Indians.

There were two responses that shared commonality of representation of famous, historic Indian leaders included in the assessment. References were made that the face of Mahatma Gandhi, a prominent Indian historical leader, would be recognized easily. An additional recommendation that was made by participants was to adapt the test to create more relatability for those living in villages and rural areas of India. A participant recited "Going to the park is not that common in rural India and villages. If these pictures were shown to villages and farmers, they might have trouble identifying the pictures. I think it would be more relevant if you kept photos of their own villages and basic symbols and tools that they use."

Processing Speed: Indian food was at the core of many participants' recommendations for adaptation of the images. Images that were used in the tests such as birthday cake and pretzels were not relatable for the participants. A few participants suggested that these images be replaced with common Indian foods and snacks such as samosas or rotis, an Indian flatbread, that are widely consumed across India. One participant shared, "So, first, there are no pretzels in India." Another participant shared, "You need to use [our] own fast food like samosa." The recommendations for this test were similar to the Picture Sequence Memory Test. One participant pointed out that a Halloween-type image was used, but Halloween is not a holiday that is celebrated in India. Others felt that the images of animals were unrelatable and suggested that they be replaced with animals commonly known in India. Examples that were given included camels, cows, and elephants.

The images that were related to climate and weather were also a focus for participants. One participant told the researcher, "It does not snow, so people would not recognize this no way. Rainbows and rain, so maybe making the photos better for the Indian weather and the climate." Snow has not been seen by many in India, especially those in the south where they only have dry and monsoon seasons. As shared by the participant, removing the snowflake and adding in rain or rainbows would help Indian participants better relate to the images.

There was also an image related to Halloween that was presented to participants on this assessment. While participants were not confused by it, most of them did not understand what it was beyond the colors of purple and orange. One participant recommended, "I think it would be difficult because they don't have Halloween religion day here, so we would want to pick 


\section{A cultural exploration of the national institutes of health neuropsychological cognition battery assessments in India}

their either temple or some sort of religion day for India so they would be recognize the event more than your Halloween."

The recommendation to change the flowers with more native flowers to India was also made. One participant stated, "Marigold flowers are very common in India. You can find them at most weddings and cultural ceremonies."

Executive Function: The Dimensional Change Card Sort Test (Zelazo, 2006) used four different images: a rabbit, a sailboat, a truck, and a volleyball. Participant experiences taking this assessment were that of confusion. The test instructed participants to quickly tap the image that matched either the shape or color of the primary image. The participant was required to focus on the word, either "SHAPE" or "COLOR," that was presented in order to accurately choose the image that matched the word. As far as the images, participants felt that the rabbit, sailboat, and truck were all culturally appropriate. Participants did suggest that the volleyball be replaced with a cricket ball, similar to recommendations made from the picture sequence memory test. No participant shared that this test was culturally inappropriate at any point during the interview process.

The primary recommendations from participants were focused on food, sports, festivals, religion, and daily life processes such as farming and cooking. Participants recommended that images of food and common snacks from the Western world be replaced with common Indian foods and snacks such as samosas or rotis, an Indian flatbread, which is widely consumed all across India. In addition, the sport of cricket plays a significant, meaningful role in the culture and history of India (Majumdar, 2003; Naha, 2015, 2017; Sen, 2015). Many participants suggested that future adaptations of the test replace the images related to baseball, football, and soccer with cricket in order to be more relatable with Indian culture. The traditions and festivals related to Diwali and Holi surfaced numerous times while participants were sharing recommendations for changing images and storylines. Participants were concerned that Indians would not relate to a story of engaging in camping or playing in the park, especially in more rural, uneducated parts of India. However, they did share that more Indians would understand and relate with images of events and traditions in which they take part. Overall, the recommendations for changing the assessments to be more culturally relevant for Indians in India focused on reflecting the processes and events of their life and not those of the Western culture. This study acknowledged the potential of social variables influencing cognition. Through the sociocultural construction perspective, the participants learned and interpreted the images as a function of their unique social and cultural environment (VandenBos, 2007). The recommendations were then manifestations of those social and cultural environments.

Many recommendations from participants focused on the inclusion of images that those living in rural India would be able to identify, understand, and relate with. Examples included cows, village homes, and farm equipment. This theme is important because it highlights the unique realities that people living in rural parts of India experience, and that urban realities are not exclusively encompassing of Indian culture. The prevalence of rural perspective demonstrated the importance of understanding and including subcultures into test adaptation.

\section{DISCUSSION}

This study acknowledged the potential of social variables influencing cognition. The framework of sociocultural construction identifies the process by which humans learn and 


\section{A cultural exploration of the national institutes of health neuropsychological cognition battery assessments in India}

think as a function of social and cultural environment (VandenBos, 2007). This theme indicated that sociocultural construction played an important role in the experiences of Indians living in India who took the assessments.

The majority of the sample came from Gujarat, which according to Gidwani (2008) and Dixit (2009) is one of India's more rural states in terms of income, agriculture, and education. The literacy rate in Gujarat is $78.03 \%$ (Gujarat Directorate of Economics and Statistics, 2017), so even with translation in this state, $21.97 \%$ of the population would not be able to take the assessments. The influence of rural Indian lifestyle became especially apparent based on participant recommendations.

The recommendations from participants to translate the assessments in Hindi or other Indian languages is directly related to all of the themes that were identified. Risager (2006) identified a complex relationship between language and culture, and in order to make the tests as culturally relevant and appropriate as possible, translation would be an important step.

Previous literature has demonstrated a strong association between an individual's education level and their performance on various neuropsychological measures (Ardila et al., 1992; Bornstein \& Suga, 1988; Finlayson et al., 1977; Leckliter \& Matarazzo, 1989; Ostrosky et al., 1985). The neuropsychological effects of age and education have been well researched and proven in the literature (Heaton, Igor, Matthews, Fastenau, \& Adams, 1996; Zarit, Miller, \& Kahn, 1978). Neuropsychological test performance is particularly influenced by education levels in cultures where education is not given a strong emphasis, assessment performance can be affected both positively and negatively (Ganguli et al., 2010). Participants expressed that the assessments were culturally acceptable for those in higher, more educated castes, but many shared concerns that individuals who are uneducated may have significant challenges understanding the images. Some even expressed concern with the potential of rural farmers in India having an understanding and relatability with the images displayed. One participant shared, "Only educated people would maybe understand." Another participant expressed, "Yes, but I will say this to give it for the educated person rather than the an uneducated one." This research supports the idea that the level of education has the potential to influence how an individual relates to cultural constructs and images that are presented. These findings are related to Vygotsky's (1978) sociocultural theory because education, or the lack thereof, can influence social interaction and the process of making meaning. Education was a sociocultural variable in this study.

A key strength of this research is that the researcher made direct contact with participants in a comfortable setting and allowed participants to describe their lived experiences of taking the assessments with a full essence of phenomenology (Lavrakas, 2008; Oltmann, 2016). In addition, evidence-based research design strategies were used in this study, including member checking, semi-structured interview questions, and reflexive journaling (Creswell, 2018). This research study was designed with sensitivity to the Indian context and cultural dimensions (Hofstede, 2001).

Another strength of this research is that the researcher was also from the Indian culture, and this was helpful in developing rapport and trust with the participants. Bell, Fahmy, and Gordon (2016) argued the importance of developing rapport in qualitative research interviewing. For this study, rapport was defined as the level of comfort in the interactions between the researcher and participants in India (Given, 2008). The interviewer was able to engage in 


\section{A cultural exploration of the national institutes of health neuropsychological cognition battery assessments in India}

casual, social conversation before and after the interview in the native language of many participants. This created a sense of trust and ease in the participants, and it facilitated honest, candid feedback sharing.

A further strength of this study was that saturation was achieved with the sample size of 30 participants (Fusch \& Ness, 2015; Hennik \& Kaiser, 2019). Achieving saturation in qualitative research is important (Lowe, Norris, Farris, \& Babbage, 2018). No new themes or information emerged after the 25th participant. The use of member checking was also a strength of this research, and it increased the validity of the findings (Birt et al., 2016). Member checking ensured accuracy throughout the interview process. Audio files were transcribed by a professional third-party transcriptionist, eliminating the potential for researcher bias in transcription. Following transcription and member checking, transcripts were carefully analyzed multiple times by hand and using MAXQDA software for accuracy in analysis and understanding. As a result of this research study, both central research questions were answered. The findings from this study will now be able to inform adaptation research of these assessments for use in India.

Acknowledging the limitations is a critical step of the research process. The potential for response bias (Lewis-Beck, Bryman, Liao, \& Sage Publications, 2004) existed with this research study. In their research, Johnson, Kulesa, Cho, and Shavitt (2005) studied the relation between culture and response styles. They found that power distance and masculinity were found to be positively and independently associated with response style. The dimensions of individualism, uncertainty avoidance, power distance, and masculinity (Hofstede, 1991) were negatively associated with response behavior in India, as well as other countries apart of the sample studied. Given the gender differences between the researcher (male) and participant (female), response bias might have impacted verbal responses within the dimension of masculinity and power distance. After conducting research on 5,569 respondents across 15 countries, Tellis and Chandrasekaran (2010) found that "socially desirable responding was highest in Singapore and Italy, yea-saying is highest in Brazil and India, and nay-saying is highest in the Netherlands and Japan" (p. 329). There is possibility that even though participants felt that the assessments were not culturally appropriate, they may have responded in a perceivably favorable manner. As with most qualitative research, it is possible that the researcher's presence during data collection might have affected the subjects' responses (Anderson, 2010).

A second limitation of this study was that a majority of participants were recruited from the state of Gujarat. Participants living in this state might have had a different experience taking the assessments when compared to other individuals living in different parts of India. Subcultures exist in India (Pattnaik, 2013), and the sample from Gujarat might not have accounted for a wide variety of potential subcultures. However, given that participants ranged in ages from 19 to 76, many subcultures were included due to the diverse age span.

The results from qualitative research studies cannot be generalized beyond the sample due to the design and methodology of qualitative investigation (Saldaña, 2011; Smith et al., 2009). There are four philosophical assumptions of qualitative research (Creswell, 2009). The ontological assumption of qualitative research is the multiple sets of realities for people living in different contexts. Therefore, research must acknowledge that there are different types of evidence. The qualitative data from this study are an important testament to this claim. The epistemological assumption of qualitative research is that researchers must get as close to the 


\section{A cultural exploration of the national institutes of health neuropsychological cognition battery assessments in India}

participants as possible in order to truly understand what is being studied. The axiological assumption is that the researcher's perspective must be critically and honestly admitted and reflected, not to be considered in a negative light. The methodological assumption is that qualitative research is an inductive and emergent process in which the researcher develops and in turn impacts the research (Creswell, 2009). While the researcher did engage in reflexive journaling during data collection and throughout data analysis, it is impossible to escape from individual subjectivity. This subjectivity from the research can result in researcher bias but given the processes that were in place to address research bias, it is unlikely that research bias influenced the findings of this study.

While it can also be viewed as a strength of this study, participant variance in education levels may have skewed the sample. Only participants who had completed the fifth grade were included in the sample. The lack of inclusion of participants without education up to this level might have yielded noninclusive findings, especially in the most rural areas of India. The same can be said for limiting the sample to individuals who were able to speak English.

This research study was carried out with paramount ethical consideration, sensitivity to the Indian culture, and with the highest standard of integrity to the field. This is a strength of this research, and it is directly related to the validity of the research findings (International Union of Psychological Science, 2008; Bamgbose, 2019). Semi-structured interviews using thoughtfully crafted questions and probes were developed in order to best answer the two research questions. The four ethical principles from the Universal Declaration of Ethical Principles for Psychologists are respect for the dignity of persons and people, competent caring for the well-being of persons and people, integrity, and professional and scientific responsibilities to the community (International Union of Psychological Science, 2008). These four principles were adhered to extremely closely throughout the entire research process.

The adaptations of the assessments will allow Indians in India to relate with the images and focus on the instructions of the task. Because the NIH Toolbox is used for diagnostic and evaluation purposes, the findings from this research study have the potential to benefit the fields of neuropsychology, clinical psychology, neurology, and other practitioners within the field of social and health sciences. Findings from this research can inform future adaptations of the assessments, and those adaptations can reduce the likelihood of misdiagnosis once the assessments are validated. For example, by using the adapted and validated NIH assessments, Indians living in India will have access to a potentially higher quality and standard of neuropsychological care. This process, ultimately, could improve the quality of life for individuals in India who may have major neuropsychiatric disorders. There are over 30 million people who have some form of neurological disorder in India (Gourie-Devi, 2014). Among these 30 million people, cognitive deficits have been shown to exist in various psychiatric disorders (Dalal \& Sivakumar, 2010).

Cultural psychology views the person and culture as cocreated and constructed. Cross-cultural psychologists aim to study the similarities and differences in psychological functioning across and between cultures (Berry et al., 2011). As a result, the implications of this study for the field of cultural psychology are focused on highlighting differences between the Indian culture and the Western culture where the NIH Toolbox assessments were developed. The findings from this study can inform cultural psychologists of the differences in lived experiences between individuals who take these assessments. 


\section{A cultural exploration of the national institutes of health neuropsychological cognition battery assessments in India}

The findings from this research study have the potential to benefit neuropsychologists, clinical psychologists, and other practitioners within the field of social sciences. The findings from this research can inform future adaptations of the assessments, and those adaptations can reduce the likelihood of misdiagnosis once the assessments are validated. This process, ultimately, could improve the quality of life for individuals in India who may have major neuropsychiatric disorders.

India is a diverse country with a strong presence of rich tradition and culture. This culture cannot be removed from the identities of the people who were born, raised, and currently living in India. Therefore, researchers and clinicians have an obligation to take culture and context into consideration when looking at the individual in India. Neuropsychological disorders are not confined exclusively to the Western culture. Such disorders can be found across diverse cultures around the world. Neuropsychological tests and assessments must be culturally appropriate in order for them to be effective with diverse populations.

\section{REFERENCES}

Affleck, W., Glass, K., \& MacDonald, M. (2013). The limitations of language: Male participants, stoicism, and the qualitative research interview. American Journal of Men's Health, 7(2), 155-162. doi:10.1177/1557988312464038

Agranovich, A., Panter, A., Puente, A., \& Touradji, P. (2011). The culture of time in neuropsychological assessment: Exploring the effects of culture-specific time attitudes on timed test performance in Russian and American samples. Journal of the International Neuropsychological Society, 17(4), 692-701. doi:10.1017/S1355617711000592

American Psychological Association. (2010). Ethical principles of psychologists and code of conduct. Retrieved from https://www.apa.org/ethics/code/

American Psychological Association. (2012). APA handbook of research methods in psychology (1st ed.). Washington, DC: American Psychological Association.

Anderson, C. (2010). Presenting and evaluating qualitative research. American Journal of Pharmaceutical Education, 74(8), 141. doi:10.5688/aj7408141

Ann, D., Kirsti, M., \& Volkert, D. (2016). Sample size in qualitative interview studies: Guided by information power. Qualitative Health Research, 26(13), 1753-1760. doi:10.1177/1049732315617444

Ardila, A. (2002). The impact of culture on neuropsychological test performance. In B. Uzzell, B. Pontón, \& A. Ardila (Eds.), International handbook of cross-cultural neuropsychology. Mahwah, NJ: Erlbaum.

Ardila, A., Rodriguez-Menendez, G., \& Rosselli, M. (2002). Current issues in neuropsychological assessment with Hispanics/Latinos. In F. R. Ferraro (Ed.), Minority and cross-cultural aspects of neuropsychological assessment (pp. 161-179). Lisse, Netherlands: Swets \& Zeitlinger.

Ardila, A., Rosselli, M., \& Ostrosky, F. (1992). Sociocultural factors in neuropsychological assessment. In A. R. Puente \& R. J. McCaffrey (Eds.), Handbook of neuropsychological assessment: A biopsychosocial perspective (pp.181-192). New York, NY: Plenum Press.

Bamgbose, G. (2019). The importance of ethics in scientific research. Lipids, 54(1), 9-11. doi:10.1002/lipd.12120

Bauer, P. J. (2002). Long-term recall memory: Behavioral and neuro-developmental changes in the first 2 years of life. Current Directions in Psychological Science, 11(4), 137141. https://doi.org/10.1111/1467-8721.00186 


\section{A cultural exploration of the national institutes of health neuropsychological cognition battery}

assessments in India

Bauer, P. J. (2006). Constructing a past in infancy: A neuro-developmental account. Trends in Cognitive Science, 10(4), 175-181.

Berg, B. L. (2007). Qualitative research methods for the social sciences. London, UK: Pearson.

Berry, J., Breugelmans, S., Chasiotis, A., \& Sam, D. (2011). Cross-cultural psychology: Research and applications. Cambridge, UK: Cambridge University Press.

Birt, L., Scott, S., Cavers, D., Campbell, C., \& Walter, F. (2016). Member checking: A tool to enhance trustworthiness or merely a nod to validation? Qualitative Health Research, 26(13), 1802-1811. doi:10.1177/1049732316654870

Boone, K. B., Victor, T. L., Wen, J., Razani, J., \& Ponton, M. (2007). The association between neuropsychological scores and ethnicity, language, and acculturation variables in a large patient population. Archives of Clinical Neuropsychology, 22(3), 355-365.

Bornstein, R. A., \& Suga, L. J. (1988). Educational level and neuropsychological performance in healthy elderly subjects. Developmental Neuropsychology, 4, 17-22.

Braun, V., \& Clarke, V. (2006) Using thematic analysis in psychology. Qualitative Research in Psychology, 3(2), 77-101.

Brickman, A., Cabo, R., \& Manly, J. (2006). Ethical issues in cross-cultural neuropsychology. Applied Neuropsychology, 13(2), 91-100.

Chapman, E., \& Smith, J. (2002). Interpretative phenomenological analysis and the new genetics. Journal of Health Psychology, 7(2), 125-130.

Charmaz, K. (2006). Constructing grounded theory: A practical guide through qualitative analysis. London, UK: Sage Publications.

Cobern, W. (1991). Contextual constructivism: The impact of culture on the learning and teaching of science. A paper presented at the Theoretical Bases for Science Education Research symposium at the Annual Meeting of the National Association for Research in Science Teaching, Lake Geneva, Wisconsin.

Crane, P. K., Narasimhalu, K., Gibbons, L. E., Mungas, D. M., Haneuse, S., Larson, E. B., ... van Belle, G. (2008). Item response theory facilitated cocalibrating cognitive tests and reduced bias in estimated rates of decline. Journal of Clinical Epidemiology, 61(10), 1018-27. e9. doi: 10.1016/j.jclinepi.2007.11.011

Creswell, J. W. (2007). Qualitative inquiry and research design: Choosing among five approaches (2nd ed.). Thousand Oaks, CA, US: Sage Publications, Inc.

Creswell, J. W. (2009). Research design: Qualitative, quantitative, and mixed methods approaches (3rd ed.). Thousand Oaks, CA: SAGE Publications, Inc.

Creswell, J., \& Poth, C. (2018). Qualitative inquiry \& research design: choosing among five approaches. Thousand Oaks, CA: SAGE.

Dalal, P., \& Sivakumar, T. (2010). Cognitive psychiatry in India. Indian Journal of Psychiatry, 52, 128-35. doi:10.4103/0019-5545.69224

Desai, N. (2010). A different freedom: Kite flying in western India: Culture and traditions. Newcastle: Cambridge Scholars.

Dikmen, S. S., Bauer, P. J., Weintraub, S., Mungas, D., Slotkin, J., Beaumont, J. L., Gershon, R., Temkin, N. R., \& Heaton, R. K. (2014). Measuring episodic memory across the lifespan: NIH Toolbox Picture Sequence Memory Test. Journal of the International Neuropsychological Society: JINS, 20(6), 611-619. https://doi.org/10.1017/S1355617714000460

Dixit, A. (2009). Agriculture in a high growth state: Case of Gujarat (1960 to 2006). Economic and Political Weekly, 44(50), 64-71.

Ellefson, M. R., Ng, F. F.-Y., Wang, Q., \& Hughes, C. (2017). Efficiency of executive function: A two-generation cross-cultural comparison of samples from Hong Kong

(c) The International Journal of Indian Psychology, ISSN 2348-5396 (e)| ISSN: 2349-3429 (p) | 1578 


\section{A cultural exploration of the national institutes of health neuropsychological cognition battery assessments in India}

and the United Kingdom. Psychological Science, 28(5), 555-566. https://doi.org/10.1177/0956797616687812

Engelmann, J. B., \& Pogosyan, M. (2013). Emotion perception across cultures: the role of cognitive mechanisms. Frontiers in Psychology, 4, 118. doi:10.3389/fpsyg.2013.00118

Finlayson, N. A., Johnson, K. A., \& Reitan, R. M. (1977). Relation of level of education to neuropsychological measures in brain damaged and non-brain damaged adults. Journal of Consulting and Clinical Psychology, 45, 536-542.

Fusch, P. I., \& Ness, L. R. (2015). Are We There Yet? Data Saturation in Qualitative Research. The Qualitative Report, 20(9), 1408-1416. Retrieved from https://nsuworks.nova.edu/tqr/vol20/iss $9 / 3$

Ganguli, M., Snitz, B. E., Lee, C. W., Vanderbilt, J., Saxton, J. A., \& Chang, C. C. (2010). Age and education effects and norms on a cognitive test battery from a populationbased cohort: the Monongahela-Youghiogheny Healthy Aging Team. Aging \& Mental Health, 14(1), 100-107. doi:10.1080/13607860903071014

Geisinger, K. F. (1992). Fairness and selected psychometric issues in the psychological testing of Hispanics. In K. F. Geisinger (Ed.), Psychological testing of Hispanics (pp. 17-42). Washington, DC: American Psychological Association.

Gidwani, V. (2008). Capital, interrupted: Agrarian development and the politics of work in India. Minneapolis, MN: University of Minnesota Press.

Given, L. M. (2008). The SAGE encyclopedia of qualitative research methods (Vols. 1-0). Thousand Oaks, CA: SAGE Publications, Inc. doi:10.4135/9781412963909

Gourie-Devi, M. (2014). Epidemiology of neurological disorders in India: Review of background, prevalence and incidence of epilepsy, stroke, Parkinson's disease and tremors. Neurology India, 62, 588-598.

Government of India. (1950). Constitution of India. Retrieved from https://www.india.gov.in/my-government/constitution-india/constitution-india-fulltext

Gujarat Directorate of Economics \& Statistics. (2017). Gujarat Integrated Statistical System. Retrieved from www.giss.gujarat.gov.in/index.jsp

Hagaman, A., \& Wutich, A. (2017). How many interviews are enough to identify metathemes in multisited and cross-cultural research? Another perspective on Guest, Bunce, and Johnson's (2006) landmark study. Field Methods, 29(1), 23-41.

Hanel, P. H., \& Vione, K. C. (2016). Do student samples provide an accurate estimate of the general public? PloS One, 11(12), e0168354. doi: 10.1371/journal.pone.0168354

Heaton, R., Igor, G., Matthews, C., Fastenau, P., \& Adams, K. (1996). Heaton, Grant, and Matthews' comprehensive norms: An overzealous attempt. Journal of Clinical and Experimental Neuropsychology, 18(3), 444-448.

Hennink, M., \& Kaiser, B. (2019). Saturation in qualitative research. In P. Atkinson, S. Delamont, A. Cernat, J. W. Sakshaug, \& R. A. Williams (Eds.), SAGE Research Methods Foundations. doi:10.4135/9781526421036822322

Hofstede, G. (1991). Cultures and organizations: Software of the mind. London, UK: McGraw-Hill.

International Union of Psychological Science. (2008). The universal declaration of ethical principles for psychologists. Retrieved from http://www.am.org/iupsys/resources/ethic s/univdecl2008.html

Jan, N. (2000). Anonymity and place in qualitative inquiry. Qualitative Inquiry, 6(4), 546569. doi:10.1177/107780040000600408 


\section{A cultural exploration of the national institutes of health neuropsychological cognition battery}

assessments in India

Johnson, T., Kulesa, P., Llc, I., Cho, Y., \& Shavitt, S. (2005). The relation between culture and response styles. Journal of Cross-Cultural Psychology, 36(2), 264-277.

Kendall, I. M., Verster, M. A., \& Von Mollendorf, J. W. (1988). Test performance of blacks in Southern Africa. In S. H. Irvine \& J. W. Berry (Eds.), Human abilities in cultural context (pp. 299-339). Cambridge: Cambridge University Press

Khilari, M., \& Narayan, S. K. (2014). The National Institute of Health Toolbox. Annals of Indian Academy of Neurology, 17(3), 247-252. doi:10.4103/0972-2327.138464

Kisser, J., Wendell, C., Spencer, R., \& Waldstein, S. (2012). Neuropsychological performance of native versus non-native English speakers. Archives of Clinical Neuropsychology, 27(7), 749-755. Retrieved from https://doi.org/10.1093/arclin/acs082

Krishnaswami, U. (2001). What is Holi? Highlights for Children, 56(3), 21.

Kuwabara, M., \& Smith, L. B. (2012). Cross-cultural differences in cognitive development: attention to relations and objects. Journal of Experimental Child Psychology, 113(1), 20-35. doi: 10.1016/j.jecp.2012.04.009

Larkin, M., Watts, S., \& Clifton, E. (2006). Giving voice and making sense in interpretative phenomenological analysis. Qualitative Research in Psychology, 3(2), 102-120.

Latha, M. (2018). Importance of English language in India: Its role in the present scenario. International Journal of Advance Engineering and Research Development, 5(2). Retrieved from http://www.ijaerd.com/papers/special_papers/ICTIMES020.pdf

Lavrakas, P. J. (2008). Encyclopedia of survey research methods (Vols. 1-0). Thousand Oaks, CA: Sage Publications, Inc. doi: 10.4135/9781412963947

Leckliter, I., \& Matarazzo, J. (1989). The influence of age, education, IQ, gender and alcohol abuse on Halstead-Reitan Neuropsychological Test Battery performance. Journal of Clinical Psychology, 45(4), 484-484.

Lewis, C., Koyasu, M., Oh, S., Ogawa, A., Short, B., \& Huang, Z. (2009). Culture, executive function, and social understanding. New Directions for Child and Adolescent Development, 123, 69-85. doi:10.1002/cd.236

Lewis-Beck, M., Bryman, A., Liao, T., \& Sage Publications. (2004). The Sage encyclopedia of social science research methods (Sage research methods online). Thousand Oaks, CA.: Sage Publications, Inc.

Lincoln, Y., \& Guba, E. (2006). Naturalistic inquiry. Newbury Park, CA: Sage Publications.

Loewenstein, D. A., Arguelles, T., Arguelles, S., \& Linn-Fuentes, P. (1994). Potential cultural bias in the neuropsychological assessment of the older adult. Journal of Clinical and Experimental Neuropsychology, 16, 623-629.

Lowe, A., Norris, A., Farris, A., \& Babbage, D. (2018). Quantifying thematic saturation in qualitative data analysis. Field Methods, 30(3), 191-207.

Majumdar, B. (2003). Cricket in India: Representative playing field to restrictive preserve. Culture, Sport, Society, 6(2/3).

Manly, J. J. (2005). Advantages and disadvantages of separate norms for African Americans. The Clinical Neuropsychologist, 19, 270-275.

Manly, J. J. (2008). Critical issues in cultural neuropsychology: Profit from diversity. Neuropsychology Review, 18, 179-183.

Mason, M. (2010). Sample size and saturation in $\mathrm{PhD}$ studies using qualitative interviews. Forum: Qualitative Social Research, 11(3).

Masuda, T., \& Nisbett, R. E. (2001). Attending holistically versus analytically: Comparing the context sensitivity of Japanese and Americans. Journal of Personality and Social Psychology, 81(5), 922-934. Retrieved from https://www.ncbi.nlm.nih.gov/pubmed/11708567 


\section{A cultural exploration of the national institutes of health neuropsychological cognition battery}

assessments in India

Matsumoto, D. (2003). Cross-cultural research. In S. F. Davis (Ed.), Handbook of research methods in experimental psychology. Oxford: Blackwell.

McBride-Chang, C., Bialystok, E., Chong, K., \& Li, Y. (2004). Levels of phonological awareness in three cultures. Journal of Experimental Child Psychology, 89, 93-111. doi: 10.1016/j.jecp.2004.05.001

McBride-Chang, C., Cho, J. R., Liu, H., Wagner, R. K., Shu, H., Zhou, A., ... Muse, A. (2005). Changing models across cultures: Associations of phonological awareness and morphological structure awareness with vocabulary and word recognition in second graders from Beijing, Hong Kong, Korea, and the United States. Journal of Experimental Child Psychology, 92(2), 140-160. doi: 10.1016/j.jecp.2005.03.009.

McNamara, C. (2009). General guidelines for conducting interviews. Retrieved January 11, 2010, from http://managementhelp.org/evaluatn/intrview.htm

Metcalf, B., \& Metcalf, T. (2012). A concise history of modern India (3rd ed.). Cambridge, England: Cambridge University Press.

Mungas, D., Reed, B., Farias, S., \& Decarli, C. (2005). Criterion-referenced validity of a neuropsychological test battery: Equivalent performance in elderly Hispanics and nonHispanic Whites. Journal of the International Neuropsychological Society, 11(5), 620630.

Naha, S. (2015). Cricket, entertainment, glamour industry and promotional culture in India, 1913-2013. Sport in History, 35(3), 464-489. doi:10.1080/17460263.2015.1088463

Naha, S. (2017). With or without cricket? The two lives of the English game in a decolonizing India. Sport in Society, 20(10), 1405-1423. doi:10.1080/17430437.2016.1221074

Northwestern University. (2009). Intro to NIH Toolbox. Retrieved from http://www.healthmeasures.net/explore-measurement-systems/nih-toolbox/intro-tonih-toolbox

Núñez, R., \& Cooperrider, K. (2013). The tangle of space and time in human cognition. Trends in Cognitive Sciences, 17(5), 220-229. https://doi.org/10.1016/j.tics.2013.03.008

Ogden, J., \& McFarlane-Nathan, G. (1997). Cultural bias in the neuropsychological assessment of young Maori men. New Zealand Journal of Psychology, 26(2), 2-12. Retrieved from https://www.psychology.org.nz/wp-content/uploads/NZJP-Vol2621997-1-Ogden.pdf

Oltmann, S. (2016). Qualitative interviews: A methodological discussion of the interviewer and respondent contexts. Forum Qualitative Sozialforschung / Forum: Qualitative Social Research, 17(2). Retrieved from http://dx.doi.org/10.17169/fqs-17.2.2551

Ostrosky, F., Canseco, E., Quintanar, L., Navarro, E., \& Ardila, A. (1985). Sociocultural effects in neuropsychological assessment. International Journal of Neuroscience, 27, 53-66.

Pade, H. (2016). The evolution of psychological testing: Embarking on the age of digital assessment. In R. Valle (Ed.), The changing faces of therapy: Innovative perspectives on clinical issues and assessment (pp. 3-33). Raleigh, NC: Lulu Publishers.

Papadopoulos, T., Georgiou, G., Deng, C., \& Das, J. (2018). The structure of speed of processing across cultures. Advances in Cognitive Psychology, 14(3), 112-125. doi:10.5709/acp-0243-7

Patricia, I., \& Lawrence, R. (2015). Are we there yet? Data saturation in qualitative research. The Qualitative Report, 20(9).

Pattnaik, B. (2013). Globalization, ICT revolution in India and socio-cultural changes: Sociological explorations. Polish Sociological Review, 181(181), 39-62.

Peterson, D. (1995). Hindus preparing for "fabulous fun" of the holiday Diwali. Star Tribune. 


\section{A cultural exploration of the national institutes of health neuropsychological cognition battery}

assessments in India

Porrselvi, A., \& Shankar, V. (2017). Status of cognitive testing of adults in India. Annals of Indian Academy of Neurology, 20(4), 334-340. doi: 10.4103/aian.AIAN_107_17

Qu, S., \& Dumay, J. (2011). The qualitative research interviews. Qualitative Research in Accounting \& Management, 8(3), 238-264.

Raskin, J. D. (2002). Constructivism in psychology: Personal construct psychology, radical constructivism, and social constructionism. In J. D. Raskin \& S. K. Bridges (Eds.), Studies in meaning: Exploring constructivist psychology (p. 1-25). Pace University Press.

Redwood, S., Gale, N., \& Greenfield, S. (2012). "You give us rangoli, we give you talk": Using an art-based activity to elicit data from a seldom heard group. BMC Medical Research Methodology, 12, 7. doi:10.1186/1471-2288-12-7

Risager, K. (2006). Language and culture: Global flows and local complexity (Languages for intercultural communication and education, 11). Clevedon: Multilingual Matters.

Rubin, H. J., \& Rubin, I. S. (1995). Qualitative interviewing: The art of hearing data. Thousand Oaks, CA: Sage Publications.

Rueda, M. R., Fan, J., McCandliss, B. D., Halparin, J. D., \& Posner, M. I. (2004). Development of attentional networks in childhood. Neuropsychologia, 42, 1029-1040.

Saldaña, J. (2016). The coding manual for qualitative researchers (3rd ed.). Los Angeles, CA: Sage Publications, Inc.

Salthouse, T., Babcock, R., \& Shaw, R. (1991). Effects of adult age on structural and operational capacities in working memory. Psychology and Aging, 6(1), 118-127. doi:10.1037//0882-7974.6.1.118

Saulton, A., Bülthoff, H., De la Rosa, S., Dodds, T., \& Herzog, M. (2017). Cultural differences in room size perception. Plos One, 12(4). doi: 10.1371/journal.pone.0176115

Saunders, B., Sim, J., Kingstone, T., Baker, S., Waterfield, J., Bartlam, B., . . Jinks, C. (2018). Saturation in qualitative research: Exploring its conceptualization and operationalization. Quality and Quantity, 52(4), 1893-1907. doi:10.1007/s11135-0170574-8

Sen, R. (2015). Nation at play: A history of sport in India (Contemporary Asia in the world). New York, NY: Columbia University Press. doi:10.7312/sen-16490

Sharp, C., Skinner, D., Serekoane, M., \& Ross, M. (2011). A qualitative study of the cultural appropriateness of the Diagnostic Interview Schedule for Children (DISC-IV) in South Africa. Social Psychiatry and Psychiatric Epidemiology, 46(8), 743-751. doi:10.1007/s00127-010-0241-z

Siriwardhana, C., Sumathipala, A., Siribaddana, S., Samaraweera, S., Abeysinghe, N., Prince, M., \& Hotopf, M. (2011). Reducing the scarcity in mental health research from lowand middle-income countries: A success story from Sri Lanka. International Review of Psychiatry, 23(1), 77-83. Retrieved from https://www.ncbi.nlm.nih.gov/pubmed/21338302

Smith, J. A., \& Osborn, M. (2004). Interpretative phenomenological analysis. In G. M. Breakwell (Ed.), Doing social psychology research (pp. 229-254). Leicester, England: British Psychological Society; Malden: Blackwell Publishing.

Smith, J. A., Flowers, P., \& Larkin, M. (2009). Interpretative phenomenological analysis: Theory, method and research. Thousand Oaks, CA: Sage Publications, Inc.

Stevens, M. J., \& Wedding, D. (Eds.). (2004). The handbook of international psychology. New York, NY: Brunner-Routledge.

Stevens, M. J., \& Zeinoun, P. (2013). International psychology. In K. Keith (Ed.), The encyclopedia of cross-cultural psychology (pp. 758-764). Hoboken, NJ: WileyBlackwell. 
Stevens, M., \& McGrath, B. (2017). A stand-alone course in international psychology. In G. J. Rich, U. P. Gielen, \& H. Takooshian (Eds.), Internationalizing the teaching of psychology (pp. 23-38). Charlotte, NC: Information Age Publishing.

Stevens, M., Benedict, A., \& Pecanha, V. de C. (2018). Foundation and parameters of a contextualized global psychology education. In K. D. Keith (Ed.), Culture across the curriculum: A psychology teacher's handbook (pp. 13-45). New York, NY: Cambridge University Press. doi:10.1017/9781316996706.004

Sullivan, G. M. (2011). A primer on the validity of assessment instruments. Journal of Graduate Medical Education, 3(2), 119-120. doi:10.4300/JGME-D-11-00075.1

Tellis, G., \& Chandrasekaran, D. (2010). Extent and impact of response biases in crossnational survey research. International Journal of Research in Marketing, 27(4), 329.

Tessier, S. (2012). From field notes, to transcripts, to tape recordings: Evolution or combination? International Journal of Qualitative Methods, 11(4).

Tripathi, R., Kumar, J. K., Bharath, S., Marimuthu, P., \& Varghese, M. (2013). Clinical validity of NIMHANS neuropsychological battery for elderly: A preliminary report. Indian journal of psychiatry, 55(3), 279-282. doi:10.4103/0019-5545.117149

VandenBos, G. R. (Ed.). (2007). APA dictionary of psychology. Washington, DC: American Psychological Association.

Vogt, P., Vogt, E., Gardner, D., \& Haeffele, L. (2014). Selecting the right analyses for your data: Quantitative, qualitative, and mixed methods. New York, NY: Guilford Press.

Vygotsky, L. S. (1978). Mind in society: The development of higher psychological processes. Cambridge, MA: Harvard University Press.

Walker, J. (2012). The use of saturation in qualitative research. Canadian Journal of Cardiovascular Nursing, 22(2), 37-46.

Weintraub, S., Dikmen, S. S., Heaton, R. K., Tulsky, D. S., Zelazo, P. D., Slotkin, J., . . . Gershon, R. (2014). The Cognition Battery of the NIH Toolbox for assessment of neurological and behavioral function: Validation in an adult sample. Journal of the International Neuropsychological Society, 20, 567-578.

Weintraub, S., Dikmen, S. S., Heaton, R. K., Tulsky, D. S., Zelazo, P. D., Bauer, P. J., ... Gershon, R. C. (2013). Cognition assessment using the NIH Toolbox. Neurology, 80(11 Suppl 3), S54-S64. doi: 10.1212/WNL.0b013e3182872ded

Zarit, S., Miller, N., \& Kahn, R. (1978). Brain function, intellectual impairment and education in the aged. The Journal of the American Geriatrics Society, 26(2), 58-67.

Zelazo, P. (2006). The Dimensional Change Card Sort (DCCS): A method of assessing executive function in children. Nature Protocols, 1(1), 297-301. doi:10.1038/nprot.200

Zelazo, P., Anderson, J., Richler, J., Wallner-Allen, K., Beaumont, J., Conway, K., . . . Weintraub, S. (2014). NIH Toolbox Cognition Battery (CB): Validation of executive function measures in adults. Journal of the International Neuropsychological Society, 20(6), 620-629. doi:10.1017/S13556177140004

\section{Acknowledgments}

We wish to thank Dr. Vijay R. Gondaliya and his team at Uka Tarsadia University in India for their support and guidance throughout the data collection process in Gujarat, India. His warm hospitality, cultural guidance, and research collaboration is greatly appreciated.

\section{Conflict of Interest}

The author declared no conflict of interest. 
How to cite this article: Bhakta, S. H, Pecanha V. D. C, Lad S. S., \& Kamath V. (2020). A cultural exploration of the national institutes of health neuropsychological cognition battery assessments in India. International Journal of Indian Psychology, 8(3), 1562-1584. DIP:18.01.159/20200803, DOI:10.25215/0803.159 